\title{
An Exploratory Study of the Knowledge and Practices of Family Caregivers in the Care of the Elderly at Home in the Buea Health District, Cameroon
}

\author{
Nahyeni Bassah*, Ukum Susan Ubenoh and John Ngunde Palle \\ Faculty of Health Sciences and Nursing, University of Buea, Buea, South West Region, Cameroon
}

\begin{abstract}
Background: Family members in Cameroon care for older relatives with little or no education on this role and no support from health care workers.
\end{abstract}

Aim: To explore the knowledge and practices of family caregivers of older adults, in order to design a health education program that can assist them in their caregiving role.

Methods: A cross-sectional community-based study design was employed, with a structured questionnaire administered to 126 primary family caregivers from 21 communities in the Buea Health District. Data was analysed using descriptive and inferential statistics.

Results: Most participants had knowledge of common problems of the elderly like joint pains (95.2\%) and difficulty walking (95.2\%), but a good number did not know about complex problems like bowel $(33.1 \%)$ and urinary $(31 \%)$ incontinence as well as elderly care resources within their communities $(88.1 \%)$. Regarding their practices, they mostly reported assisting older relatives with activities of daily living. However, a few of these relatives also reported engaging in the practice of some highly skilled healthcare task like providing their elderly relatives with automedications $(14.3 \%)$.

Conclusion: The knowledge and practices of family caregivers in the care of older relatives is generally poor and demands that training programs to enhance their care giving skills be developed. Centres that supports elderly care should create more awareness in the population about their existence and service provision.

Keywords: Family caregiving; Elderly care in Cameroon; Health education program

\section{Introduction}

The ongoing advancements in healthcare, together with improved technology and socio-economic developments relating to disease and injury [1] has resulted to significant increases in human life expectancy over the years, with a consequent need for better caregiving options for the increasing number of the older adult population [2]. The UN report on the world's population prospect in 2015 suggests that by 2050 about $22 \%$ of the world's population will be 60 years and over [3] and more than $63 \%$ of them will reside in the African region. Ageing is often accompanied by chronic illnesses and continuous deterioration of mental and physical independence, which makes caregiving more complex and challenging [4]. More so, studies suggest that more than $70 \%$ of people aged 60 and over perceive old age as a nightmare, with the uncertainty of the future and as a period where they need to depend on others for almost everything [5]. In Cameroon, a greater part of the older adult population experience poverty and social isolation as they are often on retirement, with little or no retirement plans and benefits. An exploratory study on the elderly conducted in this country [1] suggested that older adults are the most marginalized and vulnerable citizens and are dependent on family members for their basic needs.

Family caregiving is a common phenomenon in sub-Saharan Africa where the younger spouse, (often the wife) children or grandchildren have the obligation of caring for their older family members [6]. These family caregivers are expected to assist their older relatives with performing activities of daily living and preventing falls and elderly abuse [7-9]. More generally, they play a role in the physical, emotional, psychosocial and sometimes financial assistance of older family relatives who cannot care for themselves [10]. However, most of them perform this role with very little or no knowledge of care, assistance or information and support $[11,12]$. Nevertheless the family caregiving approach stands out to be better when considering the WHO's recommendation not to institutionalize the care of older adults [13] and the lack of resources for elderly care coupled with the poor socioeconomic status of families in most African countries. For example in Cameroon, there are only a few healthcare insurance policies for the elderly [14]. More so, there are limited specialised healthcare facilities for the elderly, very few geriatric nurses and only two geriatric nurse training Institutions. Family caregiving therefore can help avoid all the challenges that come along with elderly care like payment for services [15] and strengthen the family bond if adequately provided [6]. Notwithstanding, the fact that family caregivers with very little support from the government and no education on the provision of care constitute about $98 \%$ of carers of older adults in Cameroon is a call for concern $[13,16]$. Although some researchers [17] have argued that knowledge does not guarantee quality care, the lack of adequate knowledge by family caregivers can lead to unintentional harm of their loved ones, and maybe themselves $[18,19]$. Thus there is need to develop policies and educational programs to strengthen family caregiver capacity for this role, in order to promote active and healthy ageing.

*Corresponding author: Nahyeni Bassah, Faculty of Health Sciences and Nursing, University of Buea, Buea, South West Region +237 , Cameroon, Tel: +237677358661; E-mail: nahyenibassah@yahoo.com

Received May 07, 2018; Accepted May 14, 2018; Published May 18, 2018

Citation: Bassah N, Ubenoh US, Palle JN (2018) An Exploratory Study of the Knowledge and Practices of Family Caregivers in the Care of the Elderly at Home in the Buea Health District, Cameroon. J Gerontol Geriatr Res 7: 473. doi:10.4172/2167-7182.1000473

Copyright: ( $) 2018$ Bassah N, et al. This is an open-access article distributed under the terms of the Creative Commons Attribution License, which permits unrestricted use, distribution, and reproduction in any medium, provided the original author and source are credited. 
Some studies have been conducted, particularly in developed countries, on family caregiver's knowledge on the care of older adults at home. For example, Kuratal et al. [20] in 2014 used a cross-sectional study design to assess family caregivers' and homecare providers' knowledge and perceptions of physical restraint use with elders living at home in Japan. They found that family caregivers were aware of significantly fewer recognized prohibited physical restraint procedures and recognized harmful effects of physical restraint than home care providers. In another study, Garcia de Avila et al. [21] explored the level of caregiver's knowledge regarding fall prevention, and found that only $42.7 \%$ of caregivers had knowledge of fall prevention, and less than half of the participants (48.3\%) believed it was possible to prevent falls in the elderly. Chung et al. [22] examined the perceived knowledge level of dementia caregivers and the related support services available to them and found that more than half of the family caregivers knew about dementia, but their knowledge about corresponding aspects of care or available support services was not extensive. Floriano et al. [15] used semi-structured interviews to explore how family caregivers performed care to a dependent aged person and found that family caregivers were particularly involved with several everyday tasks, which are directly related to the activities of daily living like oral and body hygiene of the aged person. In addition, the family caregivers in this study also performed healthcare related task like administering their medication, taking them to a doctor's appointment, as well as other more complex activities, like measuring blood glucose and blood pressure. In yet another study, Aumann et al. [23] studied the everyday experiences of working family caregivers in providing care with their other family members, with the medical system and with their employers. They found that these caregivers generally experienced challenges relating to managing their relationship with their elderly relative, striking a balance between dependence and independence and getting the elderly relative to accept help and embrace a positive or cooperative attitude, among others. More specifically they wanted a greater work hour flexibility and more communication and support from nurses, doctors and other healthcare providers. This study therefore will assess family caregivers' knowledge, practice and needs in the care of older adults at home, in a developing country, in the Buea health district, Cameroon.

\section{Research Methodology}

\section{Study design and setting}

The study utilised an exploratory cross-sectional community-based study design. Data was collected using a structured questionnaire which solicited information on family caregivers' knowledge with regards to common problems of the elderly, elderly abuse and rights, community resource availability and usage, as well as their current practices and perceived needs relating to elderly care.

The study was conducted in the Buea Health District. Buea, the capital city of the South West Region of Cameroon, has several recreational, educational and healthcare facilities. This district has an estimated population of 169,746 inhabitants and is partitioned into seven health areas: Bokwaongo (12,519 inhabitants), Bova $(5,287$ inhabitants), Buea road (48,519 inhabitants), Buea Town (14621 inhabitants), Molyko (19,710 inhabitants), Muea (58,863 inhabitants) and Tole (10,227 inhabitants). Each health area is made up of between 8 to 15 communities.

\section{Sampling method and sample size}

A multistage sampling was done at 3 stages. In the first stage, three health areas were randomly selected, using a ballot. The Molyko health area was excluded in this study because the majority of the population are secondary school and university students.
In the next stage, seven communities were sampled from each health area using the simple random method. Thus, a total of 21 communities were selected.

Lastly, for each community, the snowballing technique was used to identify and recruit 6 participants. Thus 126 participants were recruited from the 21 communities involved. The participants were primary caregivers directly involvedin providing care to an older person over the age of 60years in their home. The snowballing sampling approach is an important strategy for finding participants of invisible or devalued populations [24], like the older adult population in this study. In each community, when the first household with an eligible participant was identified, the study was presented to the participants and they were administered the study questionnaire if they gave consent to take part in the study. At the end, the researcher requested for the availability of other potential participants from the current participant.

\section{Data analysis}

Data was analyzed using the quantitative analysis software SPSS version [21]. Descriptive analysis was done for all categorical variables by using frequencies and percentages. Chi-square tests were used to examine associations between study variables like: family caregivers' level of education and awareness of resources, family caregivers' level of education and the practice of highly skilled healthcare activities and finally family caregiver's employment status and the need for an elderly care institutions or care home to provide elderly care. Significant associations were considered for all variables with a p-value $\leq 0.05$.

\section{Ethical considerations}

Ethical approval for this study was obtained from the Institutional Review Board of the Faculty of Health Sciences of the University of Buea. Administrative approval was obtained from the South-West Regional Delegation of Public Health.

\section{Results}

\section{Demographic characteristics}

The age range of the 126 family caregivers was between 18 and 62 years and most of them were females (86.5\%). A good number of these family caregivers had attained secondary level education (51\%) and a few had attained post-secondary (29\%) education. Sixty-four percent of them were employed with either the government or private sector $(24 \%)$ and $40 \%$ were self-employed. The family caregivers in this study were mostly caring for their parents (35\%) and grandparents (25\%), while the rest (40\%) were caring for either their siblings, in-laws, spouse or other extended family members.

The age range of the older adults (care recipients) was between 60 and $93+$ years. A good number $(84.1 \%)$ of these older adults could ambulate, with a few (15.9\%) who were bed ridden. Among them, only 35 (28\%) were benefiting from pension.

\section{Family caregivers' knowledge on how to care for older adults}

Knowledge on common problems and rights of the elderly: Most of the study participants could identify that joint pains $(95.2 \%)$, difficulty walking (95.2\%), visual impairments (93.7\%), and high blood pressure $(92.9 \%)$ were problems that were most common among older adults. However, a good number did not know that urinary (31\%) and bowel (33.1\%) incontinence could also be commonly found among older adults (Table 1). With regards to older adult's rights, all the participants knew that older adults had a right to non-discrimination and the right to freedom from torture or degrading treatment. 
Knowledge on available resources on elderly care in their communities: Out of the 126 subjects, only $32(25.4 \%)$ were aware of the existence of elderly care resources within their communities that they could access for support with care like geriatric nurses, 15(11.9\%), social service centres and NGOs that cater for the elderly $13(10.3 \%)$ (Table 2).

\section{Family caregivers' practices with their older adult relatives}

Practices related to activities of daily living (ADLs) and fall prevention: Generally, most of the caregivers assisted their older relatives with a good number of ADLs, particularly with running errands (98.4\%), washing cloths (94.4\%), bathing (94.4\%) and cooking (88.9\%). However, on a general scale the study participants were not very much engaged in activities that could help prevent falls in older adults. Up to $80 \%$ said they did not help with exercises within the limits of the elderly, and $55.6 \%$ said the manner in which they arranged their home was not in consideration of the needs of the elderly.

Practices related to simple and highly skilled healthcare activities: Most of the participants reported assisting with simple healthcare task like serving prescribed medications (85.7\%), accompanying for doctor's appointments $(81.7 \%)$ and monitoring of vital signs (14.3\%). Out of the 18 subjects who cared for bed ridden elderly, 2(11\%) said they did change their care-recipient's position every 3-4 hours to prevent bedsores while $10(56 \%)$ did so only when they wanted to bath their care-recipient and $1(5 \%)$ only did so on request. In addition, $9(50 \%)$ said they changed soiled linens each time it got soiled while $2(11 \%)$ said they did so when they had the time and for $4(22 \%)$ it was only during bed bath that they changed soiled linens.

A considerable number of the study participants reported performing wound dressing at home (11.1\%), providing automedications (14.3\%) and administered injections (7.1). A statistically significant finding was observed between family caregivers' level of education and acknowledgement of performance of highly skilled health care activities ( $\mathrm{p} 0.00$ ).

Abuse related practices: All of the family caregivers reported that they did not beat or refuse food to their older relatives, but a considerable number said they yelled (32.5\%), ignored (19.5\%) or used the money of their older relative without permission (15.9\%).

\section{Perceived needs of family caregivers in the care of their older relatives at home}

Challenges faced when caring for older relative: Out of the 126 participants, $44(34.9 \%)$ cited difficulty in serving medications while $12(9.5 \%)$ expressed the feeling that their care-recipient did not like them. However, up to $102(81.6 \%)$ said they had no challenges in communicating with their older relative and $80(63.5 \%)$ said they had time for self (Table 3).

Perceived needs: The family caregivers in this study mostly expressed the need for: information on care of older adults (95.2\%), training on elderly care (88.7\%), financial assistants (87.8\%), support groups for family caregivers (83.3\%), assistance from health and social

\begin{tabular}{|c|c|c|c|c|}
\hline \multirow{3}{*}{ Health Conditions } & \multicolumn{4}{|c|}{ Responses } \\
\hline & \multicolumn{2}{|c|}{ Yes } & \multicolumn{2}{|c|}{ No } \\
\hline & Frequency & Percentage(\%) & Frequency & Percentage (\%) \\
\hline Joint pain & 120 & 95.2 & 6 & 4.8 \\
\hline Memory loss (forgetfulness) & 111 & 88.1 & 15 & 11.9 \\
\hline Visual impairment (eye problems) & 118 & 93.7 & 8 & 6.3 \\
\hline Hearing loss & 106 & 84.4 & 19 & 15.2 \\
\hline Difficulties in walking & 119 & 95.2 & 6 & 4.8 \\
\hline High blood pressure & 117 & 92.9 & 9 & 7.1 \\
\hline Urinary incontinence (cannot control urine) & 86 & 63.3 & 39 & 31 \\
\hline Bowel incontinence (cannot control stool) & 83 & 66.9 & 41 & 33.1 \\
\hline Depression & 107 & 84.9 & 19 & 15.1 \\
\hline
\end{tabular}

Table 1: Distribution of participants by awareness on common health conditions of the elderly.

\begin{tabular}{|c|c|c|c|c|}
\hline \multirow{2}{*}{ Variables (Awareness of the presence of :) } & \multicolumn{2}{|c|}{ Responses } \\
\cline { 2 - 4 } & Frequency & Percentage (\%) & Frequency \\
\hline Geriatric hospital & 25 & 29 & 101 & 94 \\
\hline Geriatric nurses & 32 & 25.4 & 111 \\
\hline Social service centres & 15 & 11.9 & 74.6 & 113 \\
\hline Non-Governmental Organisations & 13 & 10.3 & 88.1 \\
\hline
\end{tabular}

Table 2: Distribution of participants by awareness of available elderly care resources.

\begin{tabular}{|c|c|c|c|c|}
\hline \multirow{3}{*}{ Items } & \multicolumn{4}{|c|}{ Responses } \\
\hline & \multicolumn{2}{|c|}{ Yes } & \multicolumn{2}{|c|}{ No } \\
\hline & Frequency & Percentage (\%) & Frequency & Percentage (\%) \\
\hline Communication & 23 & 16.8 & 102 & 74.5 \\
\hline Serving Medications & 44 & 32.1 & 82 & 59.9 \\
\hline No time for self & 46 & 33.6 & 80 & 58.4 \\
\hline Care recipient hates me & 12 & 8.8 & 114 & 83.2 \\
\hline Lack of finances & 58 & 42.3 & 68 & 49.6 \\
\hline No time to meet up with other things & 33 & 24.1 & 93 & 67.9 \\
\hline
\end{tabular}

Table 3: Distribution of participants according to the challenges faced. 


\begin{tabular}{|c|c|c|c|c|}
\hline \multirow{3}{*}{ Perceived needs } & \multicolumn{4}{|c|}{ Responses } \\
\hline & \multicolumn{2}{|c|}{ Yes } & \multicolumn{2}{|c|}{ No } \\
\hline & frequency & Percentage (\%) & Frequency & Percentage (\%) \\
\hline Financial assistance & 108 & 87.8 & 15 & 12.2 \\
\hline Assistance from family members & 94 & 74.6 & 32 & 25.4 \\
\hline Assistance from professionals & 104 & 82.5 & 22 & 17.5 \\
\hline Material assistance & 82 & 65.1 & 44 & 34.9 \\
\hline Access to information & 120 & 95.2 & 6 & 4.8 \\
\hline More time to rest & 67 & 53.2 & 59 & 46.8 \\
\hline Support group for family caregivers & 105 & 83.3 & 21 & 16.7 \\
\hline Training on elderly care & 110 & 88.7 & 14 & 11.3 \\
\hline Institution or home for the elderly & 40 & 31.7 & 86 & 68.3 \\
\hline Flexible work program & 103 & 81.7 & 23 & 18.3 \\
\hline
\end{tabular}

Table 4: Distribution of participants according to their need for enhanced caregiving role.

care professionals $(82.5 \%)$ and flexible work program from employers $(81.7 \%)$, among others as shown on (Table 4$)$.

\section{Discussion}

The findings from this study show that family caregivers of older relatives at home in the Buea Health District have limited knowledge on the care of older adults. They assist their relatives with performing activities of daily living but are also engaged with providing highly skilled health related activities like providing auto medications and carrying out wound dressing. They found it difficult serving medications and had the feeling that their care-recipient do not like them. They expressed the need for information on care of older relatives at home, as well as support from health and social care professionals, among others.

Most of the family caregivers in this study were females between the ages of 18-51 years old, which is similar to the findings in the study of Lai and Chung [22]. Caregiving has always been associated with females as they may be more patient and understanding with people and can be more available to provide care. This dates far back to the days of Florence Nightingale who together with other women took care of wounded soldiers at the Crimean war. The caregivers in this study were still in the very active ages, suitable for caring for the elderly whose needs literature characterises as complex and usually very demanding $[25,26]$.

In this study, most of the caregivers reported taking care of either their parents or grand- parents. In the Cameroonian culture, the young are expected to look after their older relatives, and they sometimes pride themselves with this role. Moreover, most of the older adults in this study were not receiving any pension, and with the poor economic situation of the country it is cheaper to have family caregivers look after their older relatives. Furthermore, in Cameroon, the national constitution civil code obliges family members to take care of their older relatives [27]. This finding is comparable to a study in another developing country [13], where most of the family caregivers were either unemployed or self-employed, and the older adults were without any pension and had limited finances to adequately care for their older relatives.

The family caregivers in this study were generally aware of common health conditions and rights of older adults, but were not aware of more complex conditions like bowel incontinence. These results are consistent with most studies in the published literature. For example, Kuratal and Ojima [20] found a significant lack of awareness among family of recognised prohibited physical restraint procedures. Marla et al. [21] reported that more than half of their study participants lack knowledge on fall prevention, and Jasen et al. [28] found that family caregivers had limited knowledge on the management of symptoms associated with urinary incontinence. However, the gap that often exists between knowing and doing must not be ignored as knowledge does not guarantee provision of quality care [17]. This scenario is evident in this study as their practices in the care of the elderly were not very desirable. For example, although a majority of the participants knew the rights of the elderly, some of them still reported practices like yelling and ignoring that are abusive of older adults. These suggest the need for education on the rights of the elderly and how elderly abuse can be prevented.

In this study, participants, irrespective of their level of education and socioeconomic status, were remarkably ignorant about the available resources in their community that could be accessed for the care of their older relatives. The lack of knowledge on resources for elderly care in the community has also been reported [22]. Nevertheless, being aware of resources is good, but making use of them is the most important. Family caregivers should therefore be oriented on the available resources and be encouraged to maximize the benefits of such resources to ease their role as caregivers and improve their welfare.

Family caregivers have been classified as a 'shadow work force' acting as geriatric case managers, medical record keepers, paramedics, and patient advocates of their elderly care recipient [29]. In this study a few family caregivers reported performing more complex healthcare tasks like wound dressing and providing auto medications. Although family caregiving to older relatives at home could be cheaper and can strengthen the family bond [15], engaging in complex activities like these, without adequate knowledge and skills, could result to unintentional harm for these older adults, who are even more fragile. More so, the family caregivers themselves could experience back injuries during lifting, needle stick injuries during drug administration and burn out. Such practices therefore need to be discouraged and family caregivers be educated on their role and when to seek medical care and support.

This study revealed unsatisfactory practice of fall prevention among family caregivers, with a significant number $(55.6 \%)$ of the caregivers reporting not arranging their homes to be age-friendly. This seem to explain why falls are reported as common among the elderly, recording a very high prevalence in admissions, with most of the victims ending up with fractures [9]. The practices reported by caregivers of bedridden older adults showed that these older adults were at risk of developing bedsores. There is therefore a need to educate family caregivers of older adults in the Buea Health District on how to prevent falls and bedsores in the elderly. 
The act of caregiving is not an easy task and can become more tedious when one is caring for a family member who is solely depending on the caregiver for everything. This could be the reason for the many challenges and needs expressed by the study participants. This finding confirms Floriano et al. [15] findings that elderly care is an activity that leads to significant modifications in the life of the caregiver, and it can create physical, emotional and social stressors. The lack of information and lack of support from other family members and health and social care professionals to adequately cater for the elderly, can leave these caregivers with feelings of frustrations and unworthiness [30]. There is therefore a need to come up with strategies that can help minimize these challenges, to ensure a better quality of life for both the caregiver and the older relative. Training these caregivers on how to: manage their time, effectively serve medications to their care-recipient, access older adult care information and community resources, as well as educating them on some entrepreneurial income generating activities like petit businesses or on how to access funding from social service centre could be a good strategy to overcome some of these challenges. More so, support group could be created to serve as a point of contact where health and social care professionals could conduct seminars and training workshops for these family caregivers and where givers could support each other.

More than half of the participants $(62.8 \%)$ of this study did not identify an institution or home for the care of the elderly as a perceived need. This view is in line with the WHO's recommendation not to institutionalize elderly persons [13]. This may be a result of the sociocultural nature of most Africans, Cameroonians inclusive, who prefer to live with the extended family and take care of each other. Nonetheless, the fact that up to 40 (29.2\%) of the family caregivers expressed the need for an institution or home for the care of their older relatives means that stakeholders, including aged-care policy makers, health and social care professionals and insurance schemes needs to make provision for more of such services in the Buea Health District, as these caregivers may be struggling with caring for their older relatives, looking after the wider family as well as working to earn a living. Thus, they may be needing help from these institutions or homes.

\section{Conclusion}

This study has shown that family caregivers in the Buea Health District are generally aware of the common conditions and rights of the elderly. However, they were found to engage in risky practices which can be detrimental to the health of their older relatives, as well as to their own health. More so, their role was constrained by the lack of finances, insufficient time for self and difficulties with serving medications. Thus there is need for training on care of older relatives at home and how to access help and support from health and social care professionals. In this light, a health education program for family caregivers of older adults in the Buea health district could be based on the health belief model and should include content such as strategies to prevent falls and bedsores, effective communication, psychosocial support, community resource availability, creation of age-friendly environments and medication management technics, among others.

\section{References}

1. Nangia EN, Njikam M, Yenshu E (2015) Care for older persons in cameroon: Alternatives for social development. Greener J Social Sci 5: 1-12.

2. Marie NGB (2010) Social protection of the elderly: Oslo University College, Norway.

3. WHO (2015) GSAP Age Health Draft: Global strategy and action plan on ageing and health.

4. Davis LL, Gilliss CL, Harper MS (2011) Family caregiving: implications for rural practice, policy, education, and research. Rural Caregiving in the United States pp: 19-31.
5. Eboiyehi FA (2015) The perception of old age: it's implication for care and support for the aged among the Esan of South-South Nigeria. J Inter Social Res 8: 340 .

6. McDaniel SH, Pisani ARI (2012) Multiple dimensions of caregiving and disability: research, practice, policy and caregiving. Springer Science \& Business Media New York, USA.

7. Help Age International (2001) Elder abuse in the healthcare services in Kenya. Kenya.

8. WHO (2006) Global report on falls prevention in older age. Geneva: World Health Organisation.

9. Blake A (2017) Falls by elderly people at home: Prevalence and associated factors. Age Ageing 17: 365-372.

10. National Alliance for Caregiving (2010) Care for the family caregiver: a place to start: The White House Conference on Aging. Emblem health.

11. Gibson MJ, Kelly KA, Kaplan AK (2012) Family caregiving and transitional care: a critical review. family caregiver alliance. National Centre on Care Giving

12. National Association of Social Workers (2012) Aging and wellness, Social work speaks: National Association of Social Workers policy statements, 2009-2012. (8th edn). Washington, DC; NASW Press 14-21.

13. Junaiti S, Mary C, Helen E (2003) Improvement of family carers' knowledge skills and attitudes in caring for older people following the implementation of a Family carers' training program in the community in Indonesia. Indonesia: International J Nursing Practice 9: 246-254.

14. Directory of Research on Aging in Africa: 2004-2015 (2015) United Nations: New York, USA.

15. Floriano (2011) Care performed by family caregivers to dependent elderly, at home within the context of the family health strategy. Brazil 21: 3 .

16. Mary JC (1996) The Relationship between spirituality and depression in Family Caregivers of the Elderly. Graduate Research and Creative Practice.

17. Susan CR, Barbara G, Nirvana HP, Ann B (2007) Supporting family caregivers in providing care. Patient Safety and Quality: An Evidence-Based Handbook for Nurses.

18. Ballard DJ, Spreadbury B, Hopkins RS (2004) Health care quality improvemen across the baylor health care system: the first century. Proc Bayl Univ Med Cent 17: 277-288

19. Robert MM, David A, Nicewander HQ, David JB (2006) Improving quality and reducing inequities: a challenge in achieving best care. Proc Bayl Univ Med Cent 19: 103-118.

20. Kuratal S, Ojima T (2014) Knowledge, perceptions, and experiences of family caregivers and home care providers of physical restraint use with homedwelling elders: a cross-sectional study in Japan. BMC Geriatr p: 14.

21. Marla AG, Gilberto JCP, Sílvia CMB (2015) Informal caregivers of older people recovering from surgery for hip fracture caused by a fall: Fall prevention. Cien Saude Colet 20: 1901-1907.

22. Lai CK, Chung JC (20073) Addressing the informational needs of healthcare professionals in dementia care: an explorative study in a Chinese society. Aging Mental Health 7: 287-293.

23. Aumann K, Galinsky E, Sakai K, Brown M, Bond JT (2010) The elder care study: Every day realities and wishes for change. Families and Work Institute.

24. Polit D, Beck, C, Hungler B (2001) Essentials of nursing research: methods appraisal and utilization. (5th edn). Philadelphia: Lippincott, USA.

25. Jill G, Andrew S (2002) Caregiver's characteristics and needs. Family Caregivers in California.

26. Kristine W, Susan K (2010) Exploring Interventions to Reduce Cognitive Decline in Aging; J Psychosoc Nurs Ment Health Serv 48: 42-51.

27. Sanosi EF (2010) Aged people in Cameroon: Insecure as birds in the sky.

28. Jansen LS, McWilliam C, Forbes D, Forchuk C (2012) Family caregivers' experience of in-home knowledge translation. Ontario Igitur Publishing p: 12

29. Bookman A, Harrington M (2007) Family caregivers: A shadow workforce in the geriatric health care system? J Health Politics, Policy and Law 32: 1005-1041.

30. Saito M, Matsuda R, Tsudome M (2008) Problems faced by family caregivers: new challenges Japanese society faces as a result of the changing profiles of family caregivers. Institute of Human Science, Japan. 